\title{
Analysis of Strategic Management Mode and Planning Features of Entrepreneurial Enterprises
}

\author{
Qingquan Jiang ${ }^{1}$, Xiaosan Zhang $^{2}$ \\ ${ }^{1}$ School of Economics and Management, Xiamen University of Technology, Xiamen Fujian, 361005, \\ China \\ ${ }^{2}$ Xiamen National Accounting Institute, Xiamen Fujian, 361005, China
}

Key words: Entrepreneurial enterprise, Strategic management mode, Planning feature, Dimension choice.

\begin{abstract}
It offers fresh blood for all-round development of national economy and also provides lots of employment opportunities for national development. Meanwhile, it offers the guarantee for sound and stable growth of national economy. Hence, entrepreneurial enterprise is a positive promotion factor of national economic development. Therefore, it is necessary to deeply investigate strategic management mode and strategic dimension choice of entrepreneurial enterprises in the increasingly fierce market environment so as to offer effective suggestions on confirming strategy type of enterprises and choosing basic competition strategies.
\end{abstract}

\section{Introduction}

The entrepreneurial enterprise has independence. Its growth planning feature embodiment and strategic management mode choice are more important than common enterprises. The professor of Harvard Business School Michael Poter defined strategic management of enterprises as follows: strategy is the key to creating enterprise value and confirming the position of an enterprise in market operation activity. An enterprise may defeat its competitors only when it forms and keeps certain differences. Thus, entrepreneurial enterprises must well grasp strategic management mode construction and specify their development planning features[1].

\section{Analysis of basic planning features of strategic management of entrepreneurial enterprises}

Entrepreneurial enterprises have their unique features in strategic management planning. Different from traditional enterprises, entrepreneurial enterprises embody three main features in strategic management planning. Next, this paper will analyze them one by one.

\section{The complexity of overall strategic management planning is low}

Compared with complex strategic planning, strict strategic choice, deep analysis and planning formulation scheme of mature and traditional enterprises, entrepreneurial enterprises show certain simplification and low difficulty features in strategic management planning. This is mainly because the scale of entrepreneurial enterprises is usually small, and their products and market development are still in the initial exploration stage. Thus, uncertainty is large for enterprises.[2] Besides, under market economy, market strategy planning has timeliness. Some market strategy opportunities may disappear soon. For entrepreneurial enterprise, they may not own mature market grasp ability, let alone rich experience and energy to carry out fine market research. So, entrepreneurial enterprises may have a large gap with mature enterprises in this aspect. 


\section{Strategic management planning of enterprise puts particular emphasis on gaining survival and market development space}

Different from traditional enterprises or large enterprises, entrepreneurial enterprises put particular emphasis on how to survive and gain more market development space. Thus, they do not own the operation stability of mature enterprises and cannot analyze strategies in detail. However, entrepreneurial enterprises are relatively complete and all-round in the aspect of overall strategic choice.[2] On the whole, entrepreneurial enterprises should mainly solve survival problem. They continuously gain the resources for enterprise development through striving for market space, and stress how to keep a foothold in the market. So, entrepreneurial enterprises need to develop their strategies on the basis of market management and strive for breakthroughs[3].

\section{Dynamic nature of strategic management planning is strong}

Entrepreneurial enterprises show strong dynamic nature in strategic management planning, mainly because entrepreneurs carry out entrepreneurial activity due to some advantages, resources or opportunities. But their resources in all aspects are limited after they set up the enterprises, which restricts them to formulate long-term and stable strategic management planning. In one word, entrepreneurial enterprises embody strategic planning heterogeneity in different development stages, and such heterogeneity is dynamic change of enterprises in order to adapt to resource conditions[4].

\section{Interrelated theories about strategic management mode of entrepreneurial enterprises}

Entrepreneurial enterprises will face a series of complex and endless exploitation activities. To keep a foothold stably in the market, they must continuously explore growth law and influence factors of enterprises, then choose their strategic dimension in accordance with enterprise technology, internationalization and basic competition strategy of the industry, define the type of strategic management mode and finally choose the strategic management development mode suitable for them.

\section{Analysis of strategic management mode dimension choice of entrepreneurial enterprises}

Entrepreneurial enterprises should take into account of two core problems during choosing strategic management mode dimension, i.e. technological precedence and technological follow-up.[2] The two factors decide industry life cycle of enterprises and also decide important development power of enterprises. Seeing from current development trend of economic globalization, entrepreneurial enterprises mainly follow basic competition theory in terms of strategic management planning and mode choice. Thus, three strategic dimensions derive, including overall cost leadership, differentiation and focus. The development of entrepreneurial enterprises based on the above dimensions lays a solid foundation for basic competition in the market, can basically bring enterprises in the mature development period and let them own certain independence in the aspect of overall development[5].

\section{Analysis of strategic management mode of entrepreneurial enterprises}

Five strategic management modes of entrepreneurial enterprises

In accordance with three strategic dimensions of entrepreneurial enterprises in strategic management planning, this paper proposes five strategic management modes for enterprises. 


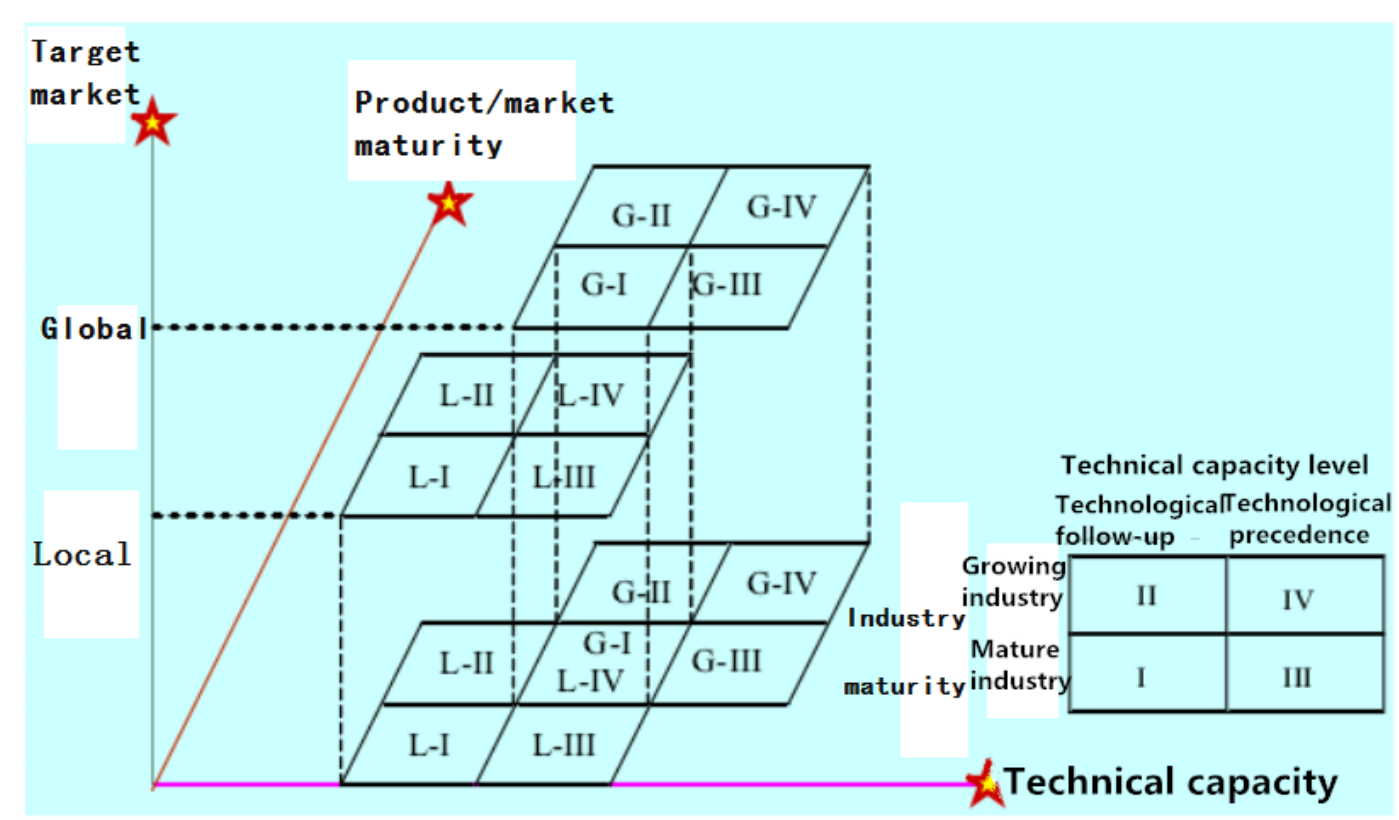

Fig.1. Schematic diagram of three dimensions of strategies of entrepreneurial enterprise

Firstly, local defensive imitation strategy. This type of strategy is applied in target market of local enterprises. The industries involved are local mature industries. Their technical level choice type is technological follow-up. These enterprises are mostly entrepreneurial enterprises. As follow-up enterprises of Chinese mature enterprises, they are in the initial development period of industry technology, i.e. exploration stage. So, their technical innovation ability is not very good, and most of them imitate mature technical products of other mature enterprises. In this way, they may occupy certain share and position in local market[6]. Secondly, local advanced strategy. Under such strategy, target market of entrepreneurial enterprises is still local market, and the industries involved are generally domestic emerging industries. Their technical level is still technological follow-up.

Thirdly, local import replacement strategy. Such strategy type is especially for mature entrepreneurial enterprises in the industry. Their technical level type is technological precedence. The uniqueness of such strategy is that its target is oriented to domestic and overseas markets. This type is suitable for all-round strategic management type of entrepreneurial enterprises. Technological precedence enterprises in domestic emerging industries including technological follow-up enterprises in international mature market will adopt such two-way strategic management mode to maximize their economic benefit[8].

Finally, follow-up strategy of international emerging industries. The technical level is technological follow-up. Generally, entrepreneurial enterprises with relatively advanced technology participate. In international emerging industries, follow-up strategy can embody development independence of enterprise technology and economy, push the existing technology to international market and form influence. These are very advantageous for rapid development of entrepreneurial enterprises[2].

\section{Case analysis}

For example, a vacuum photoelectron company is an entrepreneurial enterprise which was set up in 2000. at present, the company owns 24 proprietary intellectual property rights and have been promoted to an international high-tech enterprise. The company has strong research and development ability. Especially, its independent research success rate for large-scale vacuum photoelectron equipment is high.

Currently, the enterprise owns photoelectron thin film production base which consists of 5 complete large-scale coating production lines and also owns the production capacity of 1.10 million pieces of conducting glass. It has become the largest photoelectricity information material production base locally. The photoelectronic devices and technologies of the enterprise come from American 
peer companies, and its photoelectronic information material technology also becomes the advantage project of the enterprise. At this time, the development strategy of the company is adjusted to creative imitation strategy.

\section{Strategic management mode choice of entrepreneurial enterprises}

Strategic management mode choice of entrepreneurial enterprises should conform to practical features and abilities of enterprises and cater to the above features of strategy type. This paper briefly introduces two common strategic management modes of entrepreneurial enterprises and puts forward new strategic management modes which derive from two common strategic management modes in the new situation.

\section{Overall cost leadership strategy}

The first one is overall cost leadership strategy. Such strategy is also called low-cost strategy. Such strategy is very beneficial for entrepreneurial enterprises in the initial exploration stage. It can help enterprises reduce the cost of production, operation and advertising and create implicit advantages for rapid and cyclic development. Generally speaking, this strategy can be classified three types according to different advantage distribution methods in overall cost leadership strategy. The first type is product simplification leadership strategy. It simplifies products and eliminates various possible accessorial services in original products and services as well as directly presents product marketing essence to customers so as to improve production and operation efficiency. The second type is improved design cost strategy. The third type is material saving cost leadership strategy. Usually, overall cost leadership strategy can bring many benefits for entrepreneurial enterprises. It can avoid and restrict direct confrontation of competitors and resist initiative bargaining power of purchasers so as to flexibly handle the price rising behavior of suppliers. Meanwhile, it can establish mutual competition advantage among substitute goods. Of course, entrepreneurial enterprises will be faced with certain risks when employing overall cost leadership strategy, such as low product profit caused by the loss of market change prediction capacity, external environment and cost weakening. All these are the possible risks that enterprises may encounter under such strategy ${ }^{[9]}$.

Specific implementation steps of overall cost leadership strategy

Implementation steps of overall cost leadership strategy includes three stages: direction affirmation, objective confirmation and sparing no pains. Next, this paper will analyze them one by one.

Stage I: direction affirmation. With regard to the direction affirmation of overall cost leadership strategy, American scholar Jack.Wilch considers that the entrepreneurial enterprise must choose a direction first before implementing overall cost leadership strategy and then implements it by all means. Some scholars also propose strategic 5P (Position) and fully define direction affirmation which covers overall generalization of strategy implementation direction. Direction affirmation aims to let entrepreneurial enterprises focus on the future, achieve the long-term objective and actions and finally promote implementation of management measures. For entrepreneurial enterprises, their struggling direction and content can be called strategy. In other words, so-called "strategy" is a scheme to be chosen, and it may be contained in the enterprise resources, including human resource, finance, material and time etc.

Stage II: objective confirmation. When defining enterprise development strategy, entrepreneurial enterprises may first confirm the long-term objective and adopt a series of actions and resource allocation based on needs in order to achieve the objective. Research scholars hold that "objective confirmation" is very important, because it can let enterprise development direction more practical and specific. Enterprises may regard commercial interests as the guidance according to practical conditions of enterprises, and achieve ideal development. Besides, entrepreneurial enterprises should avoid some impractical objectives which are harmful to enterprise growth.

Stage III: sparing no pains. Entrepreneurial enterprises must spare no pains and make up their mind to implement overall cost leadership strategy, establish strategy planning and finally facilitate active cooperation of human resources, materials and time. For entrepreneurial enterprises, it can 
differentiate true and false strategies and also help enterprises reach the goal of overall cost leadership strategy. It presents the overall morale of entrepreneurial enterprises.

The second one is focus strategy. The advantage of such strategy is that the entrepreneurial enterprises with insufficient scale and capital can focus on a link or a point of operation activity and form the specific strategic management mode centered by the strategy. To be more specific, focus strategy can be classified into production line focus strategy, customer focus strategy and regional focus strategy.

Rational utilization of focus strategy has many advantages for the development of entrepreneurial enterprises. It can help enterprises integrate strength and resources and improve technical and service level based on a specific goal. This provides a favorable foundation for gradual expansion of production and operation scale. Besides, focus mode may let enterprise production sale volume become small, but product updating can continue, i.e. continuously improve research and development ability of enterprises and produce competitive products. This is very helpful for entrepreneurial enterprises to establish the brand and create basic advantages in the early stage ${ }^{[10]}$.

\section{Conclusions}

Entrepreneurial enterprises have limitations in practical strategic management and deployment process. On the one hand, their experience and economic resources are insufficient; on the other hand, market competition is cruel. Thus, entrepreneurial enterprises must achieve all-round and dynamic strategic management mode and planning features, carefully plan strategic management process based on a resource advantage, experience each growing process of enterprises and seek long-term development and self-breakthrough in the entrepreneurial environment.

\section{Acknowledgement}

Education and research project of young and middle-aged teachers in Fujian Province in 2016, Research on Influence Mechanism of Entrepreneurs' Relations on Business Mode (project No.: JAS160390)

Social science project for high-level talents in Xiamen University of Technology in 2015, Study on Influence Mechanism of Entrepreneurs' Relations of Small and Micro Enterprises, Business Mode and Enterprise Performance (project no.: YSK15013R)

\section{References}

[1] Wu Xiaoyu, Analysis on Strategic Planning of Entrepreneurial Enterprises, Technology Innovation and Application, 2012(7):202-202.

[2] Cheng Liwei, Study on Strategy Type and Growth Mode of Independent Entrepreneurial Enterprises, Southwestern University of Finance and Economics, 2007.29-34.

[3] Luo Zhengqing, Zhang Wei, Translation of Entrepreneurial Enterprise Culture under the Perspective of HR_ — Case Study of Alibaba Group, Human Resources Development of China, 2013(13):47-51.

[4] Jia Jingjing, On Management of Entrepreneurial Enterprises, China Economist, 2014(6):260-261.

[5] jia Baoqiang, Theoretical and Empirical Study on Corporate Strategic Management under Corporate Entrepreneurship Perspective, Jilin University, 2007.104-120.

[6] Tai Min, Discussion on Strategic Management of Entrepreneurial Small and Medium Enterprises, Economic Research Guide, 2016(18):11-13. 
[7] Zhang Zhongliang, Discussion on Strategic Management of Entrepreneurial Enterprises - Case Study of Sunshine Digital Company, Southwestern University of Finance and Economics, 2006.40-59.

[8] Gong Zhizhou, Study on E-commerce Entrepreneurship Pressure and Its Influence on Entrepreneurship Performance, Zhejiang University, 2005.92-106.

[9] Xie Yaping, Huang Meijiao, Summary on Model of Relationship between Entrepreneur's Entrepreneurial Competency and Performance, Technology Economics, 2013,32(5):54-61.

[10]He Xiaogang, $\mathrm{Xu}$ Shuang, Growth of Entrepreneurial Enterprises: Based on View of Entrepreneur's Power Allocation, Science \& Technology Progress and Policy, 2009,26(17):72-76. 